\title{
Circular economy as a footpath for regional development in European Union
}

\author{
Konstantina Ragazou ${ }^{1}$ and George Sklavos ${ }^{2}$ \\ ${ }^{l} P h D$ candidate in Department of Planning and Regional Development, University of Thessaly, Volos, Greece \\ ${ }^{2}$ Msc in Banking, Accounting and Finance, University of Nicosia, Nicosia, Cyprus
}

\begin{abstract}
Current linear economic model is an one-way system, based on a take, make and dispose approach. Through the years, this model became anachronistic and the European Union took the decision to replace it in 2014, by implementing a long-term action plan with the necessary financial support from European funds. Transformation of economic model started in 2016 and enhanced with "Green Agenda" agreement in 2020.

Circular economy is a systemic approach to economic growth, planned to improve corporate activities, society, and the environment. It is characterized as an economic model that introduces prevention, re-use, recycling and recovery in life cycle of products. It intends to change the production process, strengthen the supply chain management, expand digital technology and achieve development for the whole region of European Union. Innovation, network urbanisation and sustainable development are critical factors for the success of this new model.
\end{abstract}

The purpose of the research is to highlight the contribution of circular economy in European countries through a systematic literature review. Identification of appropriate bibliography, selection and critical appraisal of references lead to specify the impact of circular economy in businesses, consumers, environment and economy. This impact is characterized as positive, because of the economic growth in comparison with the development in quality of citizen's life, protection of environment and increase of income.

Keywords: Circular economy, Regional development, Impact, Sustainability, Growth

\section{Introduction}

Regional development is one of the main tools that could overpass crisis, such as the financial crisis in European Union in 2009. After many negotiations among the European Union members, Commission took the decision to enforce a circular economic model as a response to the crisis. The main challenge for the new economic model was how to meet the driving forces for regional development and contribute to the growth of European economy with a fair way among businesses, citizens and environment.

\subsection{Regional development}

Regional development is a broad term but can be seen as an effort to reduce disparities in a region through the reduction of unemployment, increase of income and economic growth. 


\section{International Virtual Conference on SOCIAL SCIENCES}

28 May, 2020

Also, regional development can lead disadvantaged communities to develop their economic, social, and environmental position, by realising the opportunities of a region's resources.

\subsubsection{Driving forces for regional development}

Regional development contributes to the reduction of regional disparities by supporting economic activities in regions. The aim of regional development is: (i) to help regions sustain their competitive advantage, (ii) to generate stronger fairer and liveable regional economies and to promote effective, and (iii) innovative governance at all levels of government. Moreover, there is a variety of motivations that lead to the development of a region:

\section{a. Economy of scope}

Transition to the digital age and development of modern science proves the high integration of industrialization and information. Improvement of economic quality and efficiency is necessary for sustainable economic development in order to deal with many problems, such as the scarcity of natural resources, ecological damage to the environment and the global carbon reduction. (Liping et al., 2018)

\section{b. Knowledge and innovation}

Many surveys show the connection between location and innovation. Innovation processes have a clear regional dimension and conditions for innovative activity differ between geographic areas. Access to knowledge, through research centres, universities, industry etc., is mainly the reason of this connection. A role of location for innovation activity mentions that at least part knowledge is specific to a certain region and shapes the innovation activities there. Example of innovative region is the Cambridge (UK) technology region. (Fritsch \& Slavtchev, 2005)

\section{c. Culture}

The role of culture in regional development is very crucial. Culture generates regional development through short-term spending impacts and long-term growth impacts. The shortterm spending impacts are associated with ability of a region to attract visitors and tourists local and non-local consumers, who spend money in the local area. The long-term growth impacts can be categorised as follow: culture as a localization factor for people, companies and investments, and the impact of culture on creativity. Culture can also have a vital role for image and knowledge of a region, in order to attract tourists and inhabitants. (Bille\&Schulze, 2006)

\section{d. Network urbanization}

Information technology, globalization and network contribute to regional economic standards and change dramatically the regional development model, by featuring new methods. In the process of urban expansion from the center to the edge, regional ties have been increasing gradually, and regionalization degree has been strengthening (Jovovic et al., 2017).

\section{e. Sustainable regional development - SRD concept}

The concept of sustainable regional development (SRD) in European Union refers to the integration of sustainable development principles into regional development practice. 


\section{International Virtual Conference on SOCIAL SCIENCES}

28 May, 2020

Accordingly, SRD encompasses all activities and instruments that promote sustainable development within regional economic initiatives. This focus is justified firstly by the important role of regions as intermediaries between national and local levels, and secondly by the growing consensus that sustainability is an essential criterion within future regional development. Furthermore, matching policy trends at European Union and national levels, each of which is moving towards much more integrated forms of operation, SRD aims to act as a catalyst in raising awareness amongst regional development professionals. It illustrates that there is no longer scope to concentrate only on economic growth, and this broader perspective encompasses activities ranging from establishing new forms of partnership to exploring innovative planning and integration methodologies. Although it represents a relatively new field, substantial knowledge and expertise in SRD already exist, and it has advanced sufficiently in theory and practice to become recognized as a specialist field with an emerging body of literature, as well as associated intellectual dilemmas and problems of realization (Jovovic et al., 2017).

\subsection{Conceptualizing Circular Economy}

Over the last decade growing attention has been paid world-wide to the new concept and development model of Circular Economy (CE), with the aim to provide a better alternative to the dominant economic development model, so called "take, make and dispose". As early as 1848, Hofman, the first President of the Royal Society of Chemistry, stated " ....in an ideal chemical factory there is, strictly speaking, no waste but only products. The better a real factory makes use of its waste, the closer it gets to its ideal, the bigger is the profit'. (Rizos et al., 2017) The term CE appears to be formally used in an economic model for the first time by Pearce \& Turner. Drawing on the principle that 'everything is an input to everything else', the authors took a critical look at the traditional linear economic system and developed a new economic model, named the CE, which applies the principles of the first and second laws of thermo dynamics (Pearce\&Turner,1990).

\subsubsection{Defining Circular Economy}

Through the years, there are many definitions for CE. Mitchell \& Morgan claims that a CE is an alternative to a traditional linear economy (take, make, dispose) in which we keep resources in use for as long as possible, extracting the maximum value from them whilst in use, then recovering and reusing products and materials. (Mitchell\&Morgan, 2015) An alternative definition introduces $\mathrm{CE}$ with intention to the impacts that this new model could create. "A circular economy provides opportunities to create well-being, growth and jobs, while reducing environmental pressures. The concept can, in principle, be applied to all kinds of natural resources, including biotic and abiotic materials, water and land'.(EEA, 2016). Also, there is an approach that utilization of sustainable energy is crucial in a circular economy. The transition to a circular economy would require addressing the challenge of establishing a sustainable energy supply as well as decisive action in several other areas such as agriculture, water, soil and biodiversity (Heshmati,2015). 


\section{International Virtual Conference on SOCIAL SCIENCES}

28 May, 2020

\subsubsection{A guide to the implementations of Circular Economy}

Companies wishing to implement a $\mathrm{CE}$ scenario can adopt four main levers: i.) circular product design, ii.) servitised business model, iii.) supply chain management and reverse logistics, and iv.) digital technologies as enablers of a CE transition.

i) The central purpose of a $\mathrm{CE}$ is to maintain the function and value of products, components and materials at the highest possible level and to extend the lifespan of such products. Product design determines to a large extent the longevity, reparability, recyclability, proportion of recycled and renewable material in the product, and its suitability for refurbishment or remanufacture. Product design therefore determines the circularity potential of a product. (EEA,2017)

ii) The introduction of servitized business models where the use or the function of a product is sold instead of the product itself, has been acknowledged as one possible enabling factor of the circular economy arena into companies. Servitization takes advantage of the digitalization of assets. Product digitalization offers valuable information and permits supervision over the lifecycle. The new digital technologies form the backbone of the fourth industrial revolution. For instance, IoT, 3D printing, Big Data and related analytics, virtual and augmented reality, has been indicated as "disruptive". Furthermore, the disruptive technologies are rapidly changing the offerings and presenting the existing service providing companies. (Martinez et al., 2019)

iii) Reverse logistics involves the collection of goods, transportation to a given location and sorting prior to remanufacturing, refurbishing, reusing or recycling or failing that, disposal. It plays an important role in the process of companies aiming to transition to a CE. Before setting up reverse flows, companies need to evaluate the supply chain within which the business operates. Companies may face hurdles such as complying with policies regulating the transport of waste as well as the unevenness of quality and quantity in return loads. There are cost challenges due to:
a. wide geographic dispersion of returns
b. inefficiencies due to lack of scale
c. sorting is labour intensive and requires space

iv) Digitalisation creates new opportunities by offering data of location, condition and availability of products. They stressed that open, accurate and big data support decision making. The digitalisation also facilitates easier and more efficient networking, collaboration and co-creation with stakeholders including customers. Marketing is also changing to become more interactive and intelligent helping companies reach and interact with consumers better than before (Antikainen et al., 2018). 


\section{International Virtual Conference on \\ SOCIAL SCIENCES}

28 May, 2020

\subsection{CE in Europe}

The first step of CE transformation in Europe comes in 2008 with the issuance of Directive 2008/98/EC of the European Parliament and of the Council, introducing definitions for waste management, "polluter pays principle" and "extended producer responsibility". Waste, recycling, secondary raw materials and recovery are some of new words that European citizens shall comply with. European Union Member States shall apply as a priority order the following waste management hierarchy:

Figure 1: Waste management hierarchy



Source: Directive 2008/98/EC

Next step comes from European Commission in 2010 with the issuance of " Europe 2020:A strategy for smart, sustainable and inclusive growth", as a response to economic crisis that took place in Europe in 2009. This strategy focus on 3 priorities:

a. Smart growth: developing an economy based on knowledge and innovation

b. Sustainable growth: promoting a more resource efficient, greener and more competitive economy.

c. Inclusive growth: fostering a high-employment economy delivering social and territorial cohesion. (EC,2010)

In 2014, European Commission communicates for first time the $\mathrm{CE}$ as a tool for implementing strategy for a smart, sustainable and inclusive growth in 2020. This communication is a roadmap for transformation to a circular economy including general information for the below:

a. Set up of a policy framework ( design of CE model, incentives for investments to $\mathrm{CE}$, actions that need to take place from businesses and consumers).

b. Define waste targets for recycling and simplifying the waste legislation

c. Set a resource efficiency target. (EC,2014) 


\section{International Virtual Conference on SOCIAL SCIENCES}

28 May, 2020

In 2015, European Commission took the decision to adopt a CE package for the transition of European businesses and consumers to the new economic model. This decision covered the full product lifecycle: from production and consumption, to waste management and the market for secondary raw materials. 650 billion euro from Horizon 2020, 5.5 billion euro from structural funds for waste management and investments for $\mathrm{CE}$ at national level was the main funding tools for the transformation of economy. Moreover, European Commission presents the Action Plan of CE transition with a timeline from 2016 up to 2018. It includes all the actions per product lifecycle stage, sectorial actions (e.g. plastic, food waste, construction and demolition etc.), investments and monitoring.

In 2020, European Commission presents the new CE Action Plan as a part of European "Green Deal". It describes all the actions that need to be enforced since 2022. The new Action Plan announces initiatives along the entire life cycle of products, targeting for example their design, promoting circular economy processes, fostering sustainable consumption, and aiming to ensure that the resources used are kept in the European Union economy for as long as possible.

It introduces legislative and non-legislative measures targeting areas where action at the European Union level brings real added value. (EC,2020)

\subsection{CE benefits European Union's economy}

$\mathrm{CE}$ advantages for economies are related to e.g., the impact on economic growth, material cost savings, mitigation of price volatility and supply risks, significant job growth in services, employment marker resilience. Laubscher and Marinelli (2014) point that companies can gain financial and reputational value. Moreover, it is a chance for companies to achieve new profit possibilities, increase competitive advantage and build resilience against several strategic challenges. Detailed advantages could concern: innovation and competitive advantage, additional revenue streams, long-term contracts, customer loyalty and feedback, multiple benefits of internal resource management, and beneficial partnerships throughout the value chain. Customer and user benefits mainly comprised of increased choice at lower cost; however, there are also some social benefits, like a contribution against climate change (Jabtonski, 2019).

\section{Methods}

This study has been undertaken as a systematic literature review. The main goal of the systematic literature review is to: (i) identify, (ii) select, and (iii) critically appraises research in order to answer a clearly formulated question (Cohen et al., 2007). Moreover, the systematic literature review it is a comprehensive, transparent search conducted over multiple databases and grey literature that can be replicated and reproduced by other researchers. It involves planning a well thought out search strategy which has a specific focus or answers a defined question. The main research question of this research is focused on the investigation of the degree of influence of the CE on the regional development in the member states of the European Union. 


\section{International Virtual Conference on \\ SOCIAL SCIENCES}

28 May, 2020

The search process was a manual search of specific journal papers and European Union's studies since early 1990. The journals and studies that were selected they were known for their use to other systematic literature reviews related to the contribution of the $\mathrm{CE}$ in regional development.

\section{Results and Discussion}

Regarding the impact of the CE, there are 4 main winners: economies, companies, user/consumers and environment. From 2016 till now, there is a gradually transition from linear to CE in Europe and the tendency is to increase the investments in this economic model after the "Green Deal" decision in 2020.

\subsection{Impact of CE in Regional Development in Europe}

After a 4-year implementation of CE, there are eleven impacts that change our lifestyle and business across the European countries, with the aim to improve our well-being, business relationships and environmental footprint.

\section{1) Substantial net material cost savings}

Based on detailed product-level modelling, medium-lived complex products industries, the CE represents a net materials cost savings opportunity of US\$ 340 to 380 billion p.a. at an European Union level for a 'transition scenario' and US\$ 520 to 630 billion p.a. for an 'advanced scenario,' net of the materials used in reverse-cycle activities in both cases. The latter range equals 19 to $23 \%$ of current total input costs, or a recurrent 3 to $3.9 \%$ of 2010 European Union GDP. Benefits in the advanced scenario are highest in the automotive sector (US\$ 170 to 200 billion p.a.), followed by machinery and equipment. (WEF, 2014)

Figure 2: Net materials cost savings opportunity 


\section{International Virtual Conference on SOCIAL SCIENCES}

28 May, 2020

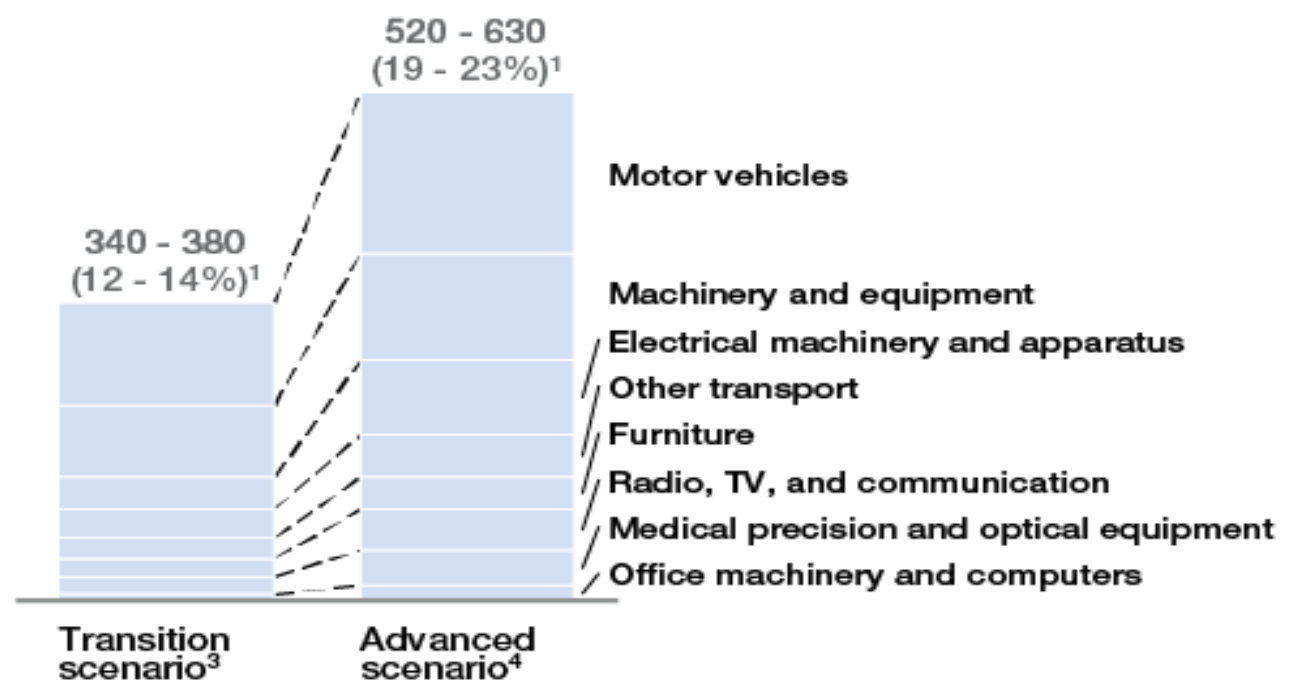

Source: World Economic Forum Report

\section{2) Growth multiplier due to sectoral shift and possible employment benefits}

A number of crucial raw materials are finite, and can be difficult or expensive to acquire in Europe. The $\mathrm{CE}$ will retain the value of the resources we use in products, returning them into the product cycle at the end of their use. New jobs will be created in innovative design and business models, research, recycling, re-manufacturing and product development. (EU, 2015) Also, it is an opportunity to turn back professions and jobs that had disappeared in recent times. According to ILO projections, "under the circular economy scenario, worldwide employment would grow by 0.1 per cent by 2030 in comparison with a business-as-usual scenario". Employment would grow in the services and waste management sectors by roughly 50 million and 45 million jobs respectively (IISD, 2018).

\section{3) Reduced externalities.}

There are sectors that many consider as mature and optimized, but it is characterized by significant waste. For example, the average European car remains parked $92 \%$ of the time, $31 \%$ of food is wasted along the value chain, and the average European office is used only $35 \%$ to $50 \%$ of the time, even during working hours. And use cycles are short. The average manufactured asset lasts only nine years (excluding buildings). In total, this way of producing and using products and resources costs Europe $€ 7.2$ trillion every year for the three sectors analyzed at depth in this report (mobility, food, and the built environment). Out of this total, actual resource costs are $€ 1.8$ trillion; other related cash costs, which include all other household and government expenditures on the three sectors, are $€ 3.4$ trillion; and externalities, such as traffic congestion, carbon, pollution, and noise, are $€ 2.0$ trillion (exhibit) (McKinsey,2015). 


\section{International Virtual Conference on \\ SOCIAL SCIENCES}

28 May, 2020

\section{4) Job creation}

Occupational mismatch may be reduced by new opportunities across all skill levels. CE deals with structural mismatch and requires new employment opportunities in high unemployment regions. The CE can also contribute to offsetting the disappearance of mid-level occupations. Sectors which provide mid-level employment, such as remanufacturing and closed loop recycling, offer potential routes to addressing the disappearance of mid-level occupations. (Mitchell\&Morgan, 2015) The employment results generally follow the same trends as GDP because rates of economic production are a key driver for employment demand. In both of the combined scenarios, employment increases by almost 0.3\% (around 650,000-700,000 jobs). These results are mainly driven by employment demand in the waste management sectors to cope with higher demand for recycled materials.(EU,2018) Specifically, 50,000 new jobs could be generated in the UK and 54,000 in the Netherlands. According to the European Commission's assessment, in the only area of waste management - says the agency - you could get even to the creation of 178,000 new direct jobs by 2030 (Cavallo\&Cencioni, 2017).

\section{5) Impact on climate change}

Across all three sectors studied (food, construction and vehicle production), the potential for greenhouse gas emission reduction is $22 \%-33 \%$ compared to 2007 levels, depending on CE scenarios considered (savings between 230-335 MtCO2eq annually). By sector: - Food: between $12 \%-14 \%$ reduction (55-64 MtCO2eq annually) - Construction: between 17\%-34\% reduction (26- $75 \mathrm{MtCO}$ eq annually) - Vehicle production: between 45\%-66\% reduction (84$123 \mathrm{MtCO} 2 \mathrm{eq}$ annually) - EEE production: between 43\%-50\% reduction (65-75 MtCO2eq annually) Altogether, the CE may lead to a reduction of $550 \mathrm{MtCO} 2 \mathrm{eq}$ annually, a 33\% reduction of the emissions related to the production of goods consumed in the EU (EIB,2018).

\section{6) Healthy and Resilient Soils}

The principles of the CE on the farming system ensure that important nutrients are returned to the soil through anaerobic processes or composting, which softens the exploitation of land and natural ecosystems. As well, since soil degradation costs an estimated US $\$ 40$ billion annually worldwide, and has hidden costs such as the increase of fertilizer use, loss of biodiversity and loss of unique landscapes - a CE could prove to be really useful for both the soils and the economy (Ellen Macarthur Foundation,2019). Also, companies reduce the environmental impact by:
a. reducing their use of raw materials
b. reducing their energy consumption and using solely green energy
c. reducing their fresh water consumption.

\section{7) The Demand For New Services on businesses}

Going towards, a circular business model would result in many more interaction points between the user and the mobility provider in comparison to today's system. European innovators could capture this opportunity and provide the services that users would demand 


\section{International Virtual Conference on SOCIAL SCIENCES}

28 May, 2020

during transit. Both incumbent industry leaders and emerging SME companies could enjoy new business opportunities, from better conference meeting facilities, to entertainment, creative commercials, and environmental services like better air quality and less noise during travel (Ellen Macarthur Foundation, 2019).

\section{8) Getting To Know Clients Better on businesses - Green Marketing}

The lessons of history teach us that one of the reasons why there is so much focus on customer experience today is because organizations are trying to force-fit new demands on top of old-style business models. Markets are littered with examples of operational processes that were built for efficiency but that lack the flexibility and personalization their customers expect. The $\mathrm{CE}$ is about the huge economic, commercial and environmental benefits from making things now that can be remade later. But while the focus is understandably about innovation and operational processes, that effort will risk being wasted without the understanding and then the execution of the right customer experiences as an integral element of the design process.

\section{9) Greater system and collaboration between companies}

$\mathrm{CE}$ is more collaborative than linear economy and focuses on the property and not so much the product as such, but its function and its use. The CE is an economy in which waste of a process of production and consumption are circulating as a new entry in the same or a different process.

All the above leads to greater collaboration between companies, but also between the public administration, research and companies themselves to find new operational solutions. Companies cannot think only about their business, but they have to assess the impact of their actions on the surrounding environment confronting all other economic actors.

\section{0) Advantages for families}

An $11 \%$ increase of disposable income, is an effect of CE. This would allow an increase in expenditure of at least $7 \%$ of GDP by 2030 . The increase of income is related to the lower costs of primary resources, is related to the use of the products (e.g. the maintenance of the vehicle, if these were shared) and those associated to external effects such as congestion and gas emissions greenhouse, which should be reduced drastically (CESME, 2018).

\section{1) Business competitiveness increase}

Prolong the productive use of materials, reuse and increase its efficiency leads to an increase in competitiveness for companies that operate in this way. The companies included in a $\mathrm{CE}$ context have an important competitive advantage over competitors with consumers. Consumers are becoming increasingly aware of how a product is made and what impact it has in the surrounding environment. Therefore, consumers prefer to buy a consumer product circular rather than linear (Botsman \& Rogers, 2010). 


\section{International Virtual Conference on SOCIAL SCIENCES}

28 May, 2020

\subsection{CE achieves regional development in Europe}

$\mathrm{CE}$ could be a holistic approach in the transformation of European economy in the after-crisis period, because action plan has in target to benefit companies, environment and citizen's lifestyle.

In business sector, $\mathrm{CE}$ is a chance to offer products in better quality and more competitive prices. Companies could achieve to reduce production cost and improve the quality of products after using recycling materials in collaboration with research centres and companies - private and public - from the same circulating chain. This co-operation facilitates knowhow expansion and exchange among the companies and also help them to be more innovative. Moreover, CE motives companies to change marketing strategy and to introduce themselves again, with a "Green" dimension in order to promote the new customer experience of product remade. The increase of demand for new services is another advantage that companies could take, especially in transition period.

For users and consumers, CE creates a new experience because of the big changes in production process and new services that sustainable development could offer. It means that product choice is more personalized to customer expect and also consumer benefits from remade process of products and cost savings of recycled materials. Products with same or better quality in lower prices is an advantage that meets the clients expectations (Nasr , 2019). New and contemporary services, such as conference meeting facilities via mobile, improve the quality of life and reduce the cost of living. CE increases family's income by changing the way we use a product and utilization of it after the end of its life.

In environmental sector, there is a drastic reduction in emissions, especially of greenhouse gas. European countries achieve to restrict the impact of climate change by changing the production process of industry. According to $\mathrm{CE}$ policy, industry reduce the use of raw material, the consumption of fresh water and the non-eco-friendly energy resources, contributing to more healthy and resilient soils.

Also, economy is the sector that has already taken advantage from this new economic model and was one of the main reasons for the over-passing of financial crisis. Improvement in business competitiveness, reduction of job unemployment due to the creation of new vacancies and increase of income, both for families and businesses, are three factors that lead in the growth of European economy. Furthermore, CE model gives the chance in European countries to reduce imports of expensive materials, through the recycling process. The circular economy will retain the value of the resources we use in products, returning them into the product cycle at the end of their use.

Last but not least, regional development is a result of CE model in Europe. This model meets the conditions for economy of scope because of the economic quality and efficiency that offers. Also, innovative products and services in comparison with information technology creates a more sustainable development in European countries, with citizens who enjoy a high quality of life. 


\section{International Virtual Conference on SOCIAL SCIENCES}

28 May, 2020

\section{Conclusion}

In 2014, European Commission took a historic decision to proceed with transformation of economic model, from linear to circular. Starting point of the new economic approach was two years later, in 2016, when the action plan for transition introduced in societies. Since 2020, a budget of at least 655 billion euro was available for the enforcement of the new concept.

Governments, businesses and citizens started a gradual implementation of new strategy. Keeping resources as long as possible, recovery and reuse of materials are the main tools for the economic growth of in an area, creation of new jobs and improvement of well-being. Moreover, CE promotes the sustainable development as a way to protect the environment against the climate change.

As of now, CE has made an impact in the economic growth of European countries. First of all, companies has increased their competitiveness through the utilization of recycled materials, achieving cost savings and accessing raw materials that produced only in third countries. Also, $\mathrm{CE}$ has created circulating chains, enhancing the collaboration among companies and the exchange of know-how. Demand for new products and services gives the chance for further growth and resilience. The creation of new vacancies has also reduce the unemployment.

Furthermore, CE offers in consumers and users products with the same or better quality and lower prices. This is an ideal combination to succeed increase of income and improve the living standards. The protection of environment with focus on healthy and resilient soils succeeds an important regional development expansion.

To sum up, CE has made a positive impact in regional development in Europe and "Green Agenda" that need to be implemented from 2020 up to 2022, is a real big challenge for a holistic transformation to a more sustainable and resilient way of life.

\section{References}

[1] Liping, F., Jun, T. and Zuting, Z. (2018). Green University: the Important Influencing Factor of Regional Development. Proceedings of the 2018 3rd International Conference on Humanities Science, Management and Education Technology (HSMET 2018). Nanjing, China, pp. 204-209.

[2] Fritsch, M. and Slavtchev, V. (2005). The Role of Regional Knowledge for Innovation. Proceedings of the $45^{\text {th }}$ ERSA conference. Amsterdam, The Netherlands.

[3] Bille, T. and Schulze, G. (2006). Culture in Urban and Regional development. Handbook of the Economics of Art and Culture, vol. 1, pp. 1051-1099.

[4] Jovovic, R., Draskovic, M., Delibasic, M. and Jovovic, M. (2017). The concept of sustainable regional development - institutional aspects, policies and prospects. Journal of international studies, vol. 10, pp. 255-266. 


\section{International Virtual Conference on SOCIAL SCIENCES}

28 May, 2020

[5] Rizos, V., Tuokko, K. and Behrens, A. (2017). The circular economy: a review of definitions, processes and impacts. CEPS Research report., Brussels, Belgium.

[6] Mitchell, P. and Morgan, J. (January 2015). Employment and the circular economy job creation in a more resource efficient Britain. WRAP. [Online]. Available: https://www.wrap.org.uk/sites/files/wrap

[7]European Environment Agency. (February 2016). Circular economy in Europe Developing the knowledge base. EEA Report. [Online]. Available: https://www.eea.europa.eu/publications/circular-economy-in-europe

[8] Heshmati, A. (2015). A review of the circular economy and its implementation. IZA Discussion Paper Series, Bonn, Germany

[9] European Environment Agency. (June 2017). Circular by design: products in the circular economy. EEA [Online]. Available: https://www.eea.europa.eu/publications/circular-by-design

[10]Martinez, U., Seneviratne, D., Villarejo, R. and Galar, D. (2019). The new asset management: Implications of Servitization in Circular Economy, Journal of industrial engineering and management science, vol. 1, pp. 109-120.

[11]Antikainen, M., Uusitalo, T. and Kivikyto-Reponen, Paivi. (2018). Digitalization as enabler of circular economy, Procedia CIRP, vol. 73, pp. 45-49.

[12]European Commission. (March 2010). EUROPE 2020: A strategy for smart, sustainable and inclusive growth. Communication from the Commission. [Online]. Available: https://eur-lex.europa.eu/legal-content/en/ALL/?uri=CELEX\%3A52010DC2020

[13]European Commission. (July 2014). Towards a circular economy: A zero waste programme for Europe. Communication from the Commission. [Online]. Available:https://ec.europa.eu/info/index_en

[14] European Commission. (March 2020). A new circular economy action plan for a cleaner and more competitive Europe. Communication from the Commission. [Online]. Available:https://eurlex.europa.eu/legalcontent/EN/TXT/PDF/?uri=CELEX:52020DC009 $\underline{8 \& \text { from }=E N}$

[15] Jabtonski, A., (2019). Sustainable Business Models, 1st ed. MDPI, Switzerland: Basel.

[16] World Economic Forum. (January 2014). Towards the circular economy: Accelerating the scale-up across global supply chains. WEF Report. [Online]. Available: http://www3.weforum.org/docs/WEF_ENV_TowardsCircularEconomy_Report_2014.pdf

[17]European Commission. (December 2015). Closing the loop-An EU action plan for the circular economy. Communication from the Commission. [Online]. Available:https://eurlex.europa.eu/legal-content/EN/TXT/PDF/?uri=CELEX:52015DC0614\&from=EN

[18]International Institute for Sustainable Development. (September 2018). Estimating employment effects of the circular economy. IISD. [Online]. Available:https://www.iisd.org/sites/default/files/publications/employment-effectscircular-economy.pdf 


\section{International Virtual Conference on SOCIAL SCIENCES}

28 May, 2020

[19] McKinsey Center for Business and Environment. (September 2015). Europe's circulareconomy opportunity. McKinsey \& Company. [Online]. Available: https://webcache.googleusercontent.com/search?q=cache:LK9m6nS8owAJ:https://www. mckinsey.com/business- functions/sustainability/our-insights/europes-circular-economyopportunity $+\& \mathrm{~cd}=3 \& \mathrm{hl}=\mathrm{en} \& \mathrm{ct}=\mathrm{clnk} \& \mathrm{gl}=\mathrm{gr}$

[20] European Commission. (May 2018). Impacts of circular economy policies on the labour economy. European Commission Report. [Online]. Available: https://op.europa.eu/en/publication-detail/-/publication/fc373862-704d-11e8-948301aa75ed71a1/language-en

[21]Cavallo, M. and Cencioni, D. (2017). Circular economy, benefits and good practice, Edizioni Ambiente, Italy: Milan.

[22]European Investment Bank. (October 2018). The EIB circular economy guide: Supporting the circular transition. [Online]. Available: https://www.eib.org/en/publications/the-eibin- the-circular-economy-guide

[23]Ellen Macarthur Foundation. (September 2019). Completing the picture. How the circular economy tackles climate change. [Online]. Available: https://www.ellenmacarthurfoundation.org/publications/completing-the-picture-climatechange

[24]CESME Interreg Europe. (2018). The CESME white book, European Regional Development Fund, Belgium:Brussels.

[25]Botsman, R. and Rogers, R. (2010). What's Mine is Yours: The rise of collaborative consumption. New York: HarperCollins.

[26] Nasr, N. (2019). Remanufacturing in the circular economy: Operations, Engineering and Logistics, $1^{\text {st }}$ ed. Scrivener Publishing LLC, U.S.A.: New York.

[27] Cohen, L., Manion, L. and Morrison, K. (2007). Research Methods in Education, $6^{\text {th }}$ ed. Routledge Taylor and Francis Group, U.S.A.: New York.

[28] Turner, A. and Pearce, D. (1990). Economics of Natural Resources and the Environment, $2^{\text {nd }}$ ed. Johns Hopkins University Press.

[29] Marinelli, T. and Laubscher, M. (2014). Integration of Circular economy in business. 